\title{
Phenotypic and Genotypic Identification of Methicillin-Resistant Coagulase Negative Staphylococcus spp. Isolated from Bovine Mastitis
}

\author{
A.G. Bhagat ${ }^{*}$, H.N. Kher, A.I. Dadawala, H.C. Chauhan, M.D. Shrimali, \\ K.B. Patel, B.K. Patel and B.S. Chandel \\ Department of Veterinary Microbiology, College of Veterinary Science and Animal \\ Husbandry, Sardarkrushinagar Dantiwada Agricultural University, \\ Sardarkrushinagar-385 506, Gujarat, India \\ *Corresponding author
}

\section{A B S T R A C T}

Keywords

Bovine mastitis, MRCoNS, PCR and Sequencing

Article Info

Accepted:

10 February 2018

Available Online:

10 March 2018
Staphylococci are one of the most prevalent microorganisms in bovine mastitis. Staphylococcus spp. are widespread in the environment, and can infect animals and humans as opportunistic pathogens. The emergence and spread of methicillin-resistant coagulase negative Staphylococcus (MRCoNS) has become a significant concern for both animal health and public health. The objective of this study was to determine the frequency of methicillin-resistance (MR) among coagulase-negative staphylococci (CoNS) in milk samples collected from bovine mastitis Identification of MRCoNS was based on both phenotypic and genotypic methods.

\section{Introduction}

India ranks first in the world in milk production and dairying in India are a classic example of production by masses rather than mass production. Among the different food sectors, the growth in dairy sector has been commendable. The rate of growth in milk production in India is also substantially higher $(3.60 \%)$ than the world average of 1.50 per cent. However, the total projected demand of milk by the year 2030 would be about 200 million tonnes, depending on assumptions about income, population, urban growth, and expenditure elasticity parameters, which would imply an annual increase of around 4 million tonnes during the next two decades (N.D.R.I., 2011). Among the several barriers in achieving the production targets, mastitis continues to remain as a challenging impediment, since the affected quarters may have 30.00 per cent less productivity and dairy animals may lose about 15.00 per cent production (Radostitis et al., 2007). In India, the overall economic loss due to mastitis is estimated to be Rs. 7165.51 crores (Bansal and Gupta, 2009). Despite intense research and control programmes, bovine mastitis has remained a major economic problem of the dairy industry (Denis et al., 2009). 
In India, a plethora of bacteria has been isolated and designated as etiological agents of mastitis in dairy animals, but Staphylococcus has been reported as the major pathogen that produces both sub-clinical and clinical intramammary infection (Sharma and Sindhu, 2007). To date, more than 50 Staphylococcus species and sub-species have been characterised to cause staphylococcal mastitis. The genus is divided into coagulase positive staphylococci and coagulase negative staphylococci (CoNS) based on their ability to coagulate plasma (Pyorala and Taponen, 2009). In addition to Staphylococcus aureus, CoNS has also become the most common bacterial pathogens isolated from milk samples in many countries causing bovine intramammary infections and could be described as emerging mastitis pathogens (de Freitas Guimaraes et al., 2013). The understanding and control of CoNS mastitis is complicated by the heterogeneity of this group of bacteria. So far, 16 CoNS species have been isolated from mastitic bovine milk samples, and despite some variation between herds and countries, S. epidermidis, S. haemolyticus, $S$. chromogenes and $S$. simulans seem to be the most common (Taponen et al., 2006). CoNS are present on the bodies of cows, and are very common in teat apices, but they are also opportunistic pathogens that can cause subclinical or clinical mastitis in cows (Taponen and Pyorala, 2009). CoNS can be involved in mastitis infection, resulting on reduced production of milk and decreased quality, causing the most important economic looses in the dairy industry (Febler et al., 2010).

Staphylococcus can be identified by conventional methods on the basis of colony morphology, biochemical and cultural characters, but it has been noted that this organism shows variations in phenotypic expressions (Khichar, 2012) and also the method of cultural examination is less sensitive and time consuming (Hegde and Isloor, 2013). Thus, PCR based diagnostic method to identify various mastitis causing pathogens is a rapid, sensitive and reliable method to resolve bacterial etiology of mastitis (Shome et al., 2012).

Staphylococci have a reputation of rapidly developing resistance to virtually any antibiotic drugs (Lentino et al., 2008). The indiscriminate treatment with antibiotics, without either a technical prescription or identification of the pathogen, can contribute to an increased resistance of these organisms, making the cure of mastitis still more difficult. Beside S. aureus, multiresistance in CoNS is worryingly common and harbour resistant genes to several antimicrobials (Silva et al., 2013). In addition, they may act as reservoirs of antimicrobial resistance genes that can be transferred to the more pathogenic S. aureus (Archer and Climo, 1994). Methicillin resistant strains in intra-mammary dissemination often produce incurable severe infections (Kumar et al., 2010).

Methicillin resistance is due to the acquisition of the mecA gene, that encodes a new protein designated PBP2a, belonging to a family of enzymes necessary in building the bacterial cell wall. PBP2a has a very low affinity for $\beta$ lactam antibiotics and confers resistance to methicillin and the other $\beta$-lactams (Pantosti et al., 2007). The transmission of bovine MRS to humans is possible and may contribute to outbreaks in human populations (Lee, 2003). Hence, it is necessary to determine the endemic strains of Staphylococcus in dairy animals which are highly pathogenic and methicillin-resistant. Sequencing of mecA gene of MRS is used to determine the genetic relationship between the animal and human isolates of MRS, to understand the role of animals as reservoir for MRS infection to humans and vice-versa (Vishnupriya et al., 2014). 
Hence this study was planned to gain insight into the presence of methicillin-resistant coagulase negative staphylococcus (MRCoNS) strains among Staphylococcus spp. isolated from bovine mastitis in Gujarat.

\section{Materials and Methods}

\section{Isolation and identification of Staphylococcus}

A total of 165 milk samples from suspected cases of mastitis were collected aseptically in sterilised vials. Milk samples were collected after cleaning the teats, discarding a few streams of milk and scrubbing the teat ends with cotton balls moistened with $70 \%$ alcohol.

Milk samples were inoculated on the plates of Nutrient Agar by spreading heavy inoculums of thoroughly mixed milk. The plates were incubated at $37^{\circ} \mathrm{C}$ for 24 hours. Thereafter, colonies showing golden yellow pigmented or white colony colour indicative of presumptive Staphylococcus were transferred to Mannitol Salt Agar which is considered as selective medium for Staphylococcus.

The colonies of Staphylococcus, forming yellow and red colouration indicative of mannitol fermentation and nonfermentation, respectively were transferred to Nutrient Agar slants for further identification. Further identification of these presumptive staphylococcal colonies was first based on conventional methods including Gram stain staining, colony morphology, catalase test and oxidase test. In addition to the biochemical tests, all the Staphylococcus spp. isolates were reidentified for confirmation using Staphylococcus genus-specific 16S rDNA gene amplification. The primers used were 16s-rDNA F GTAGGTGGCAAGCGTTA TCC and 16s-rDNA R CGCACATCAGCG TCAG (Lovseth et al., 2004)
Phenotypic and genotypic confirmation of coagulase negative Staphylococcus spp

Phenotypic and Genotypic confirmation of Coagulase negative Staphylococcus spp. were done by Coagulase test and detection of coa gene by PCR, respectively.

\section{Coagulase test}

The contents of one vial of Rabbit coagulase Plasma (0.1 g per vial, Hi-media) were aseptically rehydrated with $3 \mathrm{ml}$ of sterile distilled water and $0.5 \mathrm{ml}$ of rehydrated coagulase plasma was added in a tube. To this, 2-3 pure colonies picked from a non-inhibitory agar plate was added. After gentle mixing, the tubes were incubated at $37^{\circ} \mathrm{C}$ in incubator for up to 4 hours. Any degree of clotting within 4 hours was considered as positive result. The isolates, negative by coagulase test, were considered as a Coagulase negative Staphylococcus spp.

\section{Detection of coa gene by PCR}

All the Coagulase negative Staphylococcus spp. isolates were confirmed by absence of amplification in coa gene specific PCR. The primers used were Coa gene F ATAGAGATGCTGGTACAGG and Coa gene $\mathrm{R}$ GCTTCCGATTGTTCGATGC (Hookey et al., 1998).

Phenotypic identification of methicillin resistant coagulase negative Staphylococcus (MRCoNS) isolates

\section{Oxacillin screen agar test}

A bacterial inoculum of each strain was made and turbidity was adjusted to $0.5 \mathrm{McFarland}$. One drop of this suspension was inoculated on Mueller-Hinton agar containing 4.00 per cent of $\mathrm{NaCl}$ and $6 \mu \mathrm{g}$ of oxacillin $\mathrm{ml}^{-1}$ (Hi-Media). Plates were incubated at $35^{\circ} \mathrm{C}$ for $24 \mathrm{hrs}$. The 
strain showing growth on the plate containing oxacillin was considered to be resistant to methicillin.

\section{CHROMagar}

CHROMagar (Hi-Media) is a new chromogenic medium for the identification of MRSA. For each strain, a bacterial suspension adjusted to 0.5 McFarland was used. Subsequently, a swab was dipped in the suspension and streaked onto a CHROMagar plate. The growth of any pink to mauve colony was considered to be positive, indicating MRCoNS.

Genotypic identification of Methicillin resistant coagulase negative Staphylococcus (MRCoNS) isolates

Genotypic identification of Methicillin resistant Coagulase negative Staphylococcus (MRCoNS) were done by detection of mecA gene. The presence of the mecA gene was detected by PCR as described by Strommenger et al., (2003). Mec A DNA was amplified with the primers mecA Forward primer AAAATCGATGGTAAAGGTTGGC and mecA Reverse primer AGTTCTGCAG TACCGGATTTGC. Samples were subjected to 35 cycles consisting of $30 \mathrm{sec}$. at $94^{\circ} \mathrm{C}, 30$ sec. at $55^{\circ} \mathrm{C}$ an annealing temperature and 1 min at $72^{\circ} \mathrm{C}$ in a thermocycler. The PCR product was visualized on a $1.5 \%$ agarose gel by using ethidium bromide and a UV transilluminator.

Sequencing and phylogenetic analysis of coagulase negative methicillin resistant Staphylococcus isolates

Genomic DNA was extracted and then submitted for partial sequencing of mecA gene at the Eurofins Genomics (Bangalore, India). The DNA sequencing was performed by using Applied Biosystems BigDye® Terminator v3.1 and v1.1 Cycle Sequencing Kits with Applied Biosystems 3730xl 96 capillary DNA Analysers instrument. The specificity of the sequences obtained, the nucleotide variations and amino acid variations with respect to the $m e c A$ gene sequence of MRCoNs strains were determined using BLAST (Basic Local Alignment Search Tool) (http://blast.ncbi.nlm. nih.gov/Blast.cgi). Phylogenetic analysis was conducted for three MRCoNS isolates (SKN1, SKN-2 and SKN-3) along with Human MRCoNS isolates retrieved from the Gene Bank. The Human MRCoNS sequences retrieved from the Gene Bank (Accession number in parentheses with geographical location) were Staphylococcus epidermidis strain TN/CN/KSE/1/13 (KF415244, Tamil $\mathrm{Nadu}$ ), Staphylococcus epidermidis strain 1505 (JF710610, Pondicherry), Staphylococcus epidermidis strain BCB-F57 (GU451306, France) and Staphylococcus haemolyticus strain SH480 (AB477967, Japan).

Nucleotide sequences were aligned using the Clustal W alogarithm implemented in the Mega 6.06 program package (Center for Evolutionary Medicine and Informatics, the Biodesign Institute, USA) and Neighbor Joining tree (NJ tree) was constructed.

\section{Results and Discussion}

Isolation and identification of Staphylococcus

In primary isolation, a total of 83 Staphylococcus isolates were recovered All the 83 isolates were inoculated on Mannitol Salt Agar (MSA), wherein 78 isolates showed mannitol fermentation In Gram's stained culture smears under microscope, all the 83 isolates revealed spherical and irregular clusters like bunch of grapes. Bio-chemical characterisation revealed that all the 83 isolates were found Catalase positive and 
Oxidase negative. In genotypic confirmation by $16 \mathrm{~S}$ rDNA gene amplification, all these isolates yielded $228 \mathrm{bp}$ fragments which confirmed that all these isolates belonged to the genus Staphylococcus (Figure 1).

Phenotypic and genotypic confirmation of coagulase negative Staphylococcus spp.

Phenotypic and Genotypic confirmation of Coagulase negative Staphylococcus spp.were done by Coagulase test and detection of coa gene by PCR, respectively.

\section{Coagulase test}

Out of 83 isolates, 55 isolates were found positive for coagulase production whereas, 28 isolates found negative for coagulase production. The isolates, negative by coagulase test, were considered as a Coagulase negative Staphylococcus spp

\section{Detection of coa gene by PCR}

None of the Coagulase negative Staphylococcus spp. isolates showed amplification in coa gene specific PCR.

Phenotypic identification of methicillin resistant coagulase negative Staphylococcus (MRCoNS) isolates

\section{Oxacillin screen agar test}

Out of 28 CoNS isolates, 9 isolates showed growth on the $\mathrm{MH}$ plate containing oxacillin, which were considered as a Methicillin Resistant coagulase negative Staphylococci (MRCoNS).

\section{CHROMagar}

Out of 28 CoNS isolates, 10 isolates showed growth on the CHROMagar plate, which were considered as a MRCoNS.
Genotypic identification of Methicillin Resistant Coagulase Negative Staphylococcus (MRCoNS) isolates

The isolates, which showed phenotypic resistance to methicillin, were subjected to PCR for detection of mecA gene. Out of 10 MRCoNS isolates, 3 isolates (SKN-1, SKN-2 and SKN-3) were found to be positive for methicillin resistance targeting a 533 bp fragment (Figure 2).

Sequencing and phylogenetic analysis of coagulase negative methicillin resistant Staphylococcus isolates

All the 3 mecA positive MRCoNS isolates were successfully sequenced by ABI 3730xl 96 capillary DNA sequencing system. In the phylogenetic analysis, $m e c A$ gene sequence of all the three MRCoNS isolates showed maximum nucleotide identity with the Staphylococcus epidermidis isolates obtained from Human in Tamil Nadu followed by Pondicherry.

Bovine mastitis is a real problem for the dairy industry. The antibiotic resistance profile of the bacteria that cause this disease should be studied in order to administer the most adequate treatment. While $S$. aureus is the most important pathogen and it is broadly investigated, CoNS have been traditionally given little attention despite being considered opportunistic pathogens.

Further, they are increasingly detected as causative agents of mastitis in cows. In the present study, all the 28 presumptive strains of Coagulase negative Staphylococcus spp. isolates were identified using phenotypic and genotypic methods. Similar methods were also employed by Rusenova et al., (2013) and Anthony and Anthony (2014) for the identification of Coagulase negative Staphylococcus spp. 


\begin{tabular}{|l|r|r|r|r|r|r|r|r|}
\hline \multicolumn{7}{|c|}{ Table.1 Per cent Nucleotide Identity in MRCoNS Isolates } \\
\hline & GU451306 & AB477967 & SKN-1 & SKN-3 & SKN-2 & JF710610 & KF415244 \\
\hline GU451306 & 100.00 & 65.84 & - nan & - nan & - nan & -nan & - nan \\
\hline AB477967 & & 100.00 & 45.33 & 45.45 & 47.93 & 49.11 & 49.22 \\
\hline SKN-1 & & & 100.00 & 67.54 & 68.24 & 67.46 & $\mathbf{6 7 . 5 2}$ \\
\hline SKN-3 & & & & 100.00 & 90.62 & 86.49 & $\mathbf{8 6 . 8 7}$ \\
\hline SKN-2 & & & & & 100.00 & 94.13 & $\mathbf{9 4 . 5 3}$ \\
\hline JF710610 & & & & & & 100.00 & 99.80 \\
\hline KF415244 & & & & & & & 100.00 \\
\hline
\end{tabular}
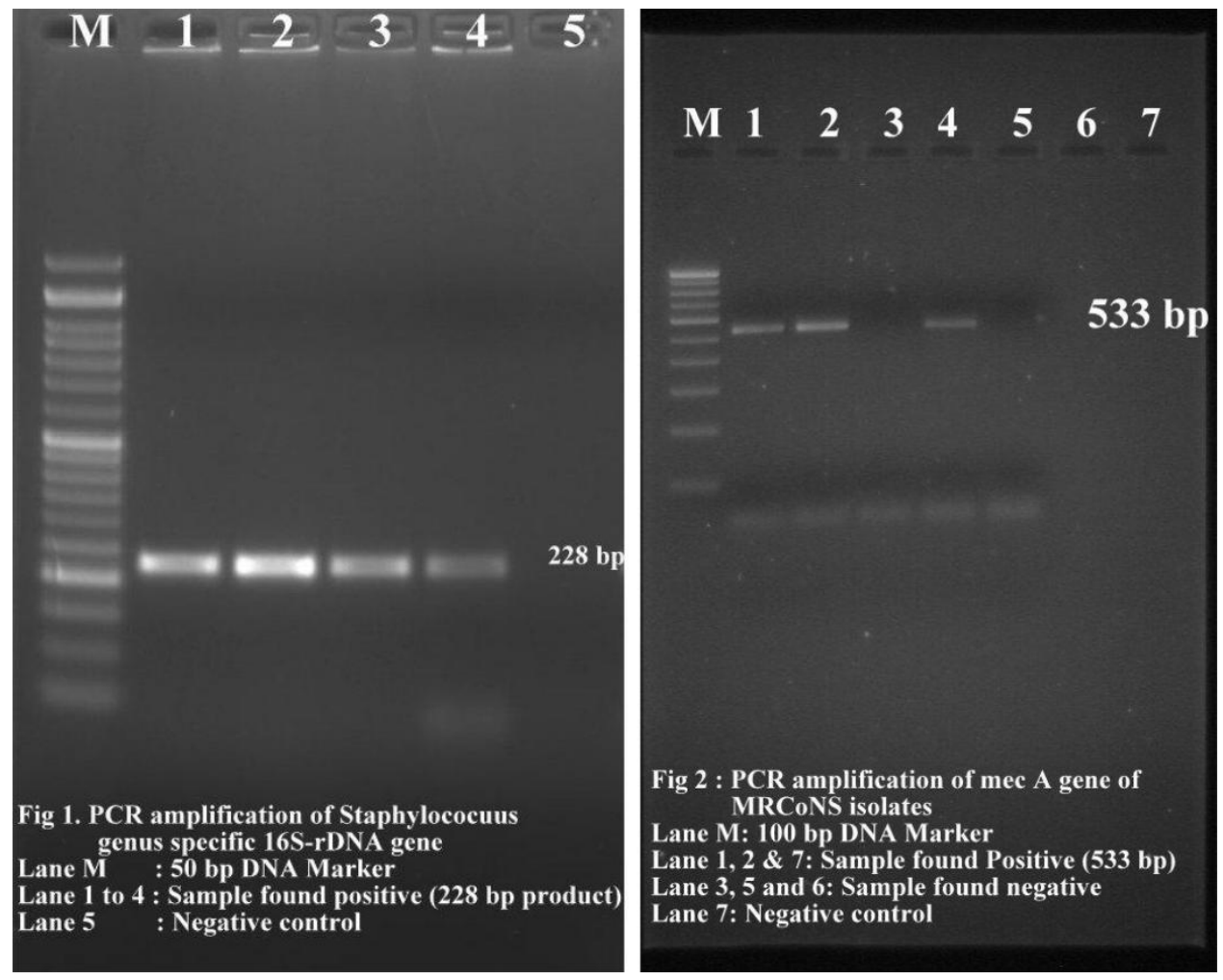

Phenotypic and genotypic confirmation of coagulase negative Staphylococcus spp

Staphylococcus is usually divided into two groups based on the ability to produce coagulase, an extracellular enzyme that clots blood plasma. The coagulase positive group that includes $S$. aureus, $S$. intermedius and some strains of Staphylococcus hyicus, whereas coagulase negative Staphylococcus (CoNS) is a large and heterogeneous group with a diverse natural habitat that contain more than 40 species and subspecies of Staphylococcus (Holt et al., 1994). Coagulase binds to protein to form a complex with thrombin-like activity which converts fibrinogen to fibrin (McDevitt et al., 1992). Coagulase produced from Staphylococcus aureus is a single chain protein with a molecular weight of $61,000 \mathrm{~d}$. Virulence of Staphylococcus aureus depends upon its ability to produce coagulase, but not with its 
ability to coagulate plasma. It is postulated that coagulase might function in some way to protect organism against the antibacterial activity of plasma which can contribute to its virulence. Coagulase is encoded by coa gene and is considered as one of the important criteria for identification of this type of organism. Many of the laboratories have utilised this property along with its combination with other tests like fermentation on MSA and production of Catalase and DNase enzymes (Kateete et al., 2010).

In the present study, out of 83 isolates, 55 isolates were found positive for coagulase production whereas, 28 isolates found negative for coagulase production. The isolates, negative by coagulase test, were considered as a Coagulase negative Staphylococcus spp. Further, None of the Coagulase negative Staphylococcus spp. isolates showed amplification in coa gene specific PCR. These results are in accordance with the study conducted by Amsaveni et al., 2010 .

\section{Phenotypic identification of MRCoNS isolates}

During recent years, methicillin resistance in animals has gained particular attention from public health authorities. It is known that the use of antimicrobials for mastitis treatment can promote emergence or survival of MRSA (Staphylococcus aureus methicillin resistant) and others methicillin resistant staphylococci in dairy cattle (Garcia-Alvarez et al., 2009). It has also been hypothesized that MRCoNS (methicillin resistant coagulase negative Staphylococcus) of agricultural animals may serve as important reservoirs for the transfer of antimicrobial resistance genes. Nevertheless, little information is available on methicillin-resistant CNS (MRCNS) from dairy cattle (Febler et al., 2010). The conventional detection assays are simple and relatively cheap methods for detecting methicillin resistance. The conventional methods to detect methicillin resistance include oxacillin agar screen test, disk diffusion using oxacillin and methicillin disk, CHROMagar method and Latex agglutination assay. In the present study, CHROMagar method and Oxacillin screen agar test were used for detection of methicillin resistant isolates.

Out of 28 CoNS isolates, 9 and 10 isolates were found as a methicillin resistant by oxacillin screen agar and CHROMagar media, respectively. CHROMagar was found superior to the oxacillin screen agar methods for phenotypic detection of methicillin resistant isolates. Similar findings were also observed by Taguchi et al., (2004) and Karthy et al., (2009). Higher sensitivity of CHROM agar in this study might be attributed to the fact that CHROMagar with cefoxitin supplement was potent inducer of the mecA gene; this could explain why heterogeneous MRS populations that variably express the $m e c A$ gene are better detected by CHROMagar with cefoxitin than medium with oxacillin, which is a weak inductor of PBP2a production. Furthermore, it was less affected by the hyper production of penicillinases, it required no special incubation temperature as was required when the testing was done with oxacillin screen agar (Mallick and Basak, 2010 and Mathews et al., 2010).

\section{Genotypic identification of MRCoNS isolates}

Accurate detection of methicillin resistance in Staphylococcus by routine methods is difficult due to the presence of two subpopulation of Staphylococcus aureus (i.e., one susceptible and other resistant) which may coexist within a culture. All the cells in culture may carry the genetic information for resistance, but a 
small numbers can express this kind of resistance in routine susceptibility testing performed in the laboratory. This phenomenon is termed as heterogeneous resistance and occurs in Staphylococcus resistant to penicillinase stable penicillin such as methicillin and oxacillin (Cavassini et al., 1999). The basis of most methicillin resistance is the production of an additional penicillin-binding protein, $\mathrm{PBP} 2$ ' or $\mathrm{PBP} 2 \mathrm{a}$, mediated by the mecA gene which is an additional gene found in methicillin resistant Staphylococcus and with no allelic equivalent in methicillin susceptible Staphylococcus. As the majority of methicillin resistant staphylococci harbour the mec $A$ gene, test based on amplification such as PCR have identified even the most heterogenous strains correctly. In the present study, 10 phenotypical MRCoNS isolates from bovine mastitis were analysed by PCR for the presence of mecA gene. The mecA gene was detected only in 3 of 10 . Thus, seven Coagulase negative Staphylococcus isolates phenotypically resistant to methicillin in this study did not carry mecA gene. This type of discrepancy in correlation between the mecA gene and phenotypically methicillin resistance has been reported earlier by Schnellmann et al., (2006) and Moon et al., (2007). The possible reasons for this type of discrepancy are that the isolates appeared to show poor expression of mecA genes or production of methicillinase (alteration of PBP subtypes) or seem to overproducing $\beta$-lactamase. The phenotypic expression of resistance could vary due to growth conditions which are also involved in the expression of methicillin resistance (Zmantar et al., 2008 and Turkylmaz et al., 2010).

\section{Sequencing and phylogenetic analysis of MRSA isolates}

There are increasing reports on MRS infection or colonization in animals and their zoonotic potential (Schnellmann et al., 2006; Weese et al., 2006 and Kaszanyitzky et al., 2007). However, a few veterinary reports have compared the mecA gene from animal isolates with human MRS strains (Malik et al., 2006 and Schnellmann et al., 2006). Hence, the present study was also intended for comparison of the $m e c A$ gene from animal MRCoNS isolates with the human MRCoNS strains available on Gene Bank.

The nucleotide sequence analysis of the present investigation showed that the mecA gene from bovine mastitis MRCoNS isolates (SKN-1, SKN-2 and SKN-3) were closely related to human MRCoNS strains (Table 1). The same results were also stated for the presence of mecA genes from bovine mastitis (Vishnupuriya et al., 2014) dogs, cats (Malik et al., 2006) and horses (Schnellmann et al., 2006). Based on the results from the present study and the other studies (Seguin et al., 1999; vanDuijkeren et al., 2004 and Malik et al., 2006), it can be construed that these isolates might have originally come from humans, considering that the methicillin resistance among human Staphylococcus isolates is common.

MRCoNS need special attention because they can be implicated in bovine mastitis. Furthermore, MRCoNS may constitute a reservoir of novel and diverse antimicrobial resistance genes and antimicrobial genetic structures that can be transferred to other pathogenic bacteria. Periodic surveillance for antimicrobial resistance patterns of MRCoNS isolated from dairy cows with mastitis could be an important measure in detecting the emergence and spreading of such resistance.

\section{Acknowledgement}

The authors are thankful to the Ministry of Minority Affairs, UGC, for the financial assistance in the form of Maulana Azad 
National Fellowship and to the Dean, College of Veterinary Science and Animal Husbandry, Sardarkrushinagar for providing the necessary facilities.

\section{References}

Amasaveni, A., Antony, P. X., Mukhopadhyay, H. K., Pillai, R. M., Vijayalakshmi, P., Thanislass, J. and Subbareddy, K.V. (2010) Detection of beta Lactamase activity in Staphylococci isolated from bovine mastitis, Indian Vet J, 87(7): 647.

Anthony, A. A. and Anthony I.O. (2014). Species diversity and antibiotic resistance properties of Staphylococcus of farm animal origin in Nkonkobe Municipality, South Africa. Folia Microbiol., 59:133-140.

Archer, G.L. and Climo, M.W. (1994). Antimicrobial susceptibility of coagulase negative staphylococci. Antimicrob. Agents Chemother., 38: 2231-2237.

Bansal, B.K. and Gupta, D.K. (2009). Economic analysis of bovine mastitis in India and Punjab -

Cavassini, M., Wenger, A., Jaton, K., Blanc, D.S. and Bille, J. (1999). Evaluation of MRSA screen, a simple anti-PBP2a slide latex agglutination kit for rapid detection of methicillin resistance in Staphylococcus aureus. J. Clin. Microbiol., 37:1591-1594.

De Freitas, G.F., Nobrega, D.B., Richini, P.V.B., Marson, P.M., Figueiredo, P.J.C. and Langoni, H. (2013). Enterotoxin genes in Coagulase-negative and Coagulase-positive staphylococci isolated from bovine milk. $J$. Dairy Sci., 96: 2866-2872.

Denis, M.D.N., Wedlock, S.J., Lacy-Hulbert, J.E., Hillerton and Bundle, B.M. (2009). Vaccines against bovine mastitis in New Zealand context: what is the best way forward. New Zealand. Vet. J., 57 (3): 132140.

Febler, A., Scott, C., Kadlec, K., Ehricht, R., Monecke, S. and Schwarz, S. (2010). Characterisation of methicillin-resistant Staphylococcus aureus ST398 from cases of bovine mastitis. J. Antimicrob. Chemother., 65 (4): 619-625.
Garcia-Alvarez, L., Lindsay, H., Brown, D.F., Curran, M.D., Walpole, E., Holden, M.T., Maskell, D.J., Bentley, S.D., Webb, C.R. and Holmes, M.A. (2009). Discovery and characterisation of a novel bovine associated methicillin-resistant Staphylococcus aureus isolate. ASM Conferences Methicillin-Resistant Staphylococci in Animals: Veterinary and Public Health Implications, Sept. 22-25, London, p. 35.

Hegde, R. and Isloor, S. (2013). Trends in diagnosis of bovine mastitis. Proceedings of Model training course on "Bovine mastitis: theoretical and practical consideration in management." PD_ADMAS. Bangalore. pp. 15-24.

Holt, J.G., Krieg, N.R., Sneath, P.H.A., Staley, J.T. and Williams, S.T. (1994). Gram positive cocci. In: Bergey's Manual of Determinative Bacteriology, edited by Hensyl, W.R. $9^{\text {th }}$ Edn. Williams and Wilkins, Baltimore. pp. 527-558.

Hookey, J.V., Richardson, J.F. and Cookson, B.D. (1998). Molecular typing of Staphylococcus aureus based on PCR restriction fragment length polymorphism and DNA sequence analysis of Coagulase gene. J. Clin. Microbiol., 36: 1083-1089.

Karthy, E.S., Ranjitha, P. and Mohankumar, A. (2009).Performance of CHROMagar and Oxacillin Resistant Screening Agar Base media for detection of Methicillin Resistant Staphylococcus aureus (MRSA) from Chronic Wound. Modern App. Sci., 3 (5): 51-56.

Kaszanyitzky, E.J., Janosi, S., Somogyi, P., Dan, A., van der Graaf-van Bloois, L., van Duijkeren, E. and Wagenaar, J.A. (2007). MRSA transmission between cows and humans. Emer. Infect. Dis., 13 (4):630-632.

Kateete, D.P., Kimani, C.N., Katabazi, F.A., Okeng, A., Okee, M.S., Nanteza, A., Joloba, M.L. and Najjuka, F.C. (2010). Identification of Staphylococcus aureus: DNAse and Mannitol salt agar improve the efficiency of the tube Coagulase test. Annals Clin. Microbiol. Antimicrob., 9. p. 23.

Khichar, V., Kataria, A.K. and Sharma, R. (2012). Characterisation of Staphylococcus aureus 
of cattle mastitis origin for two virulence associated genes (coa and spa). Comp. Clin. Path., DOI: 10.1007/s00580-012-1675-5.

Kumar, R., Yadav, B.R. and Singh, R.S. (2010). Genetic determinants of antibiotic resistance in aureusisolates from milk of mastitic crossbred cattle. Curr.Microbiol., 60: 379-386.

Lee, J.H. (2003). Methicillin (Oxacillin)-resistant Staphylococcus aureus strains isolated from major food animals and their potential transmission to humans. Appl. Environ. Microbiol., 69: 6489-6494.

Lentino, J.R., Narita, M. and Yu, V.L. (2008).New antimicrobial agents as therapy for resistant gram-positive cocci. European J. Clin. Microbiol. Infect. Dis., 27: 3-15.

Lovseth, A., Loncarevic, S. and Berdal, K.G. (2004). Modified multiplex PCR method for detection of pyrogenic Exotoxins genes in staphylococcal isolates. J. Clin. Microbiol., 42: 3869-3872.

Malik, S., Peng, H. and Barton, M.D. (2006). Partial nucleotide sequencing of the mecA gene of Staphylococcus aureus isolates from Cats and Dogs. J. Clin. Microbiol., 44(2): 413-416.

Mallick, S.K. and Basak, S. (2010). MRSA - too many hurdles to overcome; a study from central India. Trop. Doct., 40:108-110.

Mathews, A. A., Thomas, M., Appalaraju, B. and Jayalakshmi, J. (2010).Evaluation and comparison of tests to detect methicillin resistant Staphylococcus aureus.Indian J. Pathol.Microbiol., 53(1): 79-82.

McDevitt, D., Vaudaux, P. and Foster, T.J. (1992). Genetic evidence that bound Coagulase of Staphylococcus aureus is not clumping factor. Infect. Immun., 60: 15141523.

Moon, J.S., Lee, A.R., Kang, H.M., Lee, E.S., Joo, Y.S., Park, Y.H., Kim, M.N. and Koo, H.C. (2007). Antibiogram and Coagulase diversity in Staphylococcal Enterotoxin producing Staphylococcus aureus from bovine mastitis. J. Dairy Sci., 90: 17161724.

N.D.R.I. (2011). Vision-2030. National Dairy Research Institute, Karnal (Haryana), India.

Pantosti, A., Sanchini, A. and Monaco, M. (2007). Mechanisms of antibiotic resistance in
Staphylococcus aureus. Future Microbiol., 2: 323-334.

Pyorala, S. and Taponen, S. (2009). Coagulasenegative staphylococci-Emerging mastitis pathogens. Vet. Microbiol., 134 (1-2): 3-8.

Radostitis, O.M., Gay, C.C., Blood, D.C. and Hinchcliff, K.W. (2007). A textbook of diseases of cattle, sheep, pigs, goats and horses. $9^{\text {th }}$ Edn. Bailliere Tindally., pp. 2428.

Rusenova, N., Gebreyes, W., Koleva, M., Mitev, J., Penev, T., Vasilev, N. and Miteva, T. (2013). Comparison of three methods for routine detection of Staphylococcus aureus isolated from bovine mastitis. Kafkas Univ. Vet.Fak.Derg., 19(4): 709-712.

Schnellmann, C., Gerber, V., Rossano, A., Jaquier, V., Panchaud, Y., Doherr, M.G., Thomann, A., Straub, R. and Perreten, V. (2006). Presence of new mecA and $\mathrm{mph}(\mathrm{C})$ variants conferring antibiotic resistance in Staphylococcus spp. isolated from the skin of horses before and after clinic admission. J. Clin. Microbiol., 44: 4444-4454.

Schnellmann, C., Gerber, V., Rossano, A., Jaquier, V., Panchaud, Y., Doherr, M.G., Thomann, A., Straub, R. and Perreten, V. (2006). Presence of new mecA and $\mathrm{mph}(\mathrm{C})$ variants conferring antibiotic resistance in Staphylococcus spp. isolated from the skin of horses before and after clinic admission. J. Clin. Microbiol., 44: 4444-4454.

Seguin, J.C., Walker, R.D., Caron, J.P., Kloos, W.E., George, C.G., Hollis, R.J., Jones, R.N. and Pfaller, M.A. (1999). Methicillin resistant Staphylococcus aureus outbreak in a veterinary teaching hospital: potential human-to-animal transmission. J. Clin. Microbiol., 37: 1459-1463.

Sharma, A. and Sindhu, N. (2007).Occurrence of clinical and sub-clinical mastitis in buffaloes in state of Haryana.ItalianJ. Anim. Sci., 6(2): 965-967.

Shome, B.R., Das, M.S., Bhuvana, M., Krithiga, N., Shome, R., Velu, D. and Prabhudas, K. (2012). Multiplex PCR for the detection of five important Staphylococcus spp. in bovine sub-clinical mastitis milk. Indian J. Anim. Sci., 82(1): 9-14.

Silva, N.C.C., Guimaraes, F.F., Manzi, M.P., Budri, P.E., Gomez-Sanz, E., Benito, D., 
Langoni, H., Rall, V.L.M. and Torres, C. (2013). Molecular characterisation and clonal diversity of methicillin susceptible Staphylococcus aureus in milk of cows with mastitis in Brazil. J. Dairy Sci., 96: 6856-6862.

Strommenger, B., Kettlitz, C. and Werner, G. (2003). Multiplex PCR Assay for simultaneous detection of nine clinically relevant antibiotic resistance genes in Staphylococcus aureus. J. Clin. Microbiol., 41: 4089-4094.

Taguchi, H., Kaneko, T., Onozaki, M., Kubo, R. and Kamiya S. (2004).Evaluation of a new Chromogenic medium for isolation of MRSA.J. Japanese Assoc. Infect. Dis., 78: 54-58.

Taponen, S., Simojoki, H., Haveri, M., Larsen, H.D. and Pyorala, S. (2006). Clinical characteristics and persistence of bovine mastitis caused by different species of Coagulase negative staphylococci identified with API or AFLP. Vet. Microbiol., 115: 199-207.

Turkyilmaz, S., Tekbyk, S., Oryasin, E. and Bozdogan, B. (2010). Molecular epidemiology and antimicrobial resistance mechanisms of methicillin resistant
Staphylococcus aureus isolated from bovine milk. Zoonoses Pub. Hlth., 57: 197203.

Van Duijkeren, E., Box, A.T.A., Heck, M.E.O.C., Wannet, W.J.B. and Fluit, A.C. (2004). Methicillin resistant staphylococci isolated from animals. Vet. Microbiol., 103: 91-97.

Vishnupriya, S., Antony, P.X., Mukhopadhyay, H.K., Pillai, R.M., Thanislass, J., Vivek Srinivas, V.M. and Sumanth Kumar, R. (2014). Methicillin resistant Staphylococci associated with bovine mastitis and their zoonotic importance. Vet. World., 7(6): 422-427.

Weese, J., Caldwell, F., Willey, B., Kreiswirth, B., McGeer, A., Rousseau, J. and Low, D. (2006). An outbreak of methicillin resistant Staphylococcus aureus skin infections resulting from horse to human transmission in a veterinary hospital. Vet. Microbiol., 114: 160-164.

Zmantar, T., Chaieb, K., Ben Abdallah, F., Ben Kahla, N.A., Ben Hassen, A., Mahdouani, K. and Bakhrouf, A. (2008). Multiplex PCR detection of the antibiotic resistance genes in Staphylococcus aureusstrains isolated from auricular infections. Folia Microbiol., 53(4): 357-362.

\section{How to cite this article:}

Bhagat, A.G., H.N. Kher, A.I. Dadawala, H.C. Chauhan, M.D. Shrimali, K.B. Patel, B.K. Patel and Chandel, B.S. 2018. Phenotypic and Genotypic Identification of Methicillin-Resistant Coagulase Negative Staphylococcus spp. Isolated from Bovine Mastitis. Int.J.Curr.Microbiol.App.Sci. 7(03): 1110-1120. doi: https://doi.org/10.20546/ijcmas.2018.703.132 